\title{
PENDAMPINGAN KADER POS PEMBINAAN TERPADU (POSBINDU) KELOMPOK BIMBINGAN IBADAH HAJI DAN UMROH
}

\author{
Administration Of Integrated Development Post Office (POSBINDU) Guidance \\ Group For Hajj And Umrah Worship
}

\author{
Anggraini Dwi Kurnia ${ }^{1}$, Nur Melizza ${ }^{1 *}$, Nur Lailatul Masruroh ${ }^{1}$, Cici Endang \\ Setyowati ${ }^{2}$ \\ ${ }^{1}$ Departemen Komunitas, Fakultas Ilmu Kesehatan, Universitas Muhammadiyah \\ Malang \\ ${ }^{2}$ Puskesmas Ciptomulyo \\ E-mail:melizza@umm.ac.id
}

\begin{abstract}
Abstrak
Kesehatan pada Kelompok Bimbingan Ibadah Haji dan Umroh juga menjadi perhatian bagi keperawatan komunitas. Kondisi Kesehatan akan sangat menunjang dalam memperlancar proses ibadah. Tujuan dari kegiatan pengabdian masyarkat ini adalah untuk meningkatan kesehatan jemaah melalui peningkatan pengetahuan dan keterampilan kader posbindu agar dapat melakukan pengontrolan kesehtan berkala melalui kegiatan posbindu. Pelatihan masyarakat dikemas dalam bentuk pelatihan kader posbindu dengan menggunakan metode ceramah dan demonstrasi. Metode ini memiliki beberapa keunggulan diantaranya, dapat membuat pengajaran menjadi lebih jelas dan konkret, sehingga menghindari verbalisme (pemahaman secara kata-kata atau kalimat), peserta lebih mudah memahami apa yang dipelajari, proses pengajaran lebih menarik, dan peserta dirangsang untuk aktif mengamati, menyesuaikan antara teori dengan kenyataan dan mencoba melaukannya sendiri. Peserta yang telibat merupakan beberapa jama'ah dan pengurus sejumlah 12 orang yang terdiri dari 6 perempuan dan 6 laki-laki. Usia peserta antara 41-60 tahun, setelah diberikan ceramah dan demonstrasi tingkat pengetahuan peserta $100 \%$ dalam kategori baik. Hasil ini didapatkan melalui evaluasi tes yang dilaksanakan setelah rangkaian kegiatan pelatihan. Kegiatan pengabdian masyarakat efektif meningkatkan pengetahuan dan keterampilan peserta sebagai kader posbindu yaitu dengan memahami pengetahuan terkait penyakit umum, persiapan sebagai calon jemaah haji dan tindakan pemeriksaan dasar dalam kegiatan posbindu.
\end{abstract}

Kata kunci: Posbindu, Haji dan Umroh, Pendampingan

\begin{abstract}
Health in the Hajj and Umrah Guidance Group is also a concern for community nursing. Health conditions will be very supportive in expediting the process of worship. The purpose of this community service activity is to improve the health of the congregation through increasing the knowledge and skills of the cadre of posbindu so that they can carry out regular health control through the posbindu activity. Community training is packaged in the form of posbindu cadre training using lecture and demonstration methods. This method has several advantages including, can make teaching clearer and more concrete, so as to avoid verbalism (understanding in words or sentences), participants more easily understand what is learned, the teaching process is more interesting, and participants are stimulated to actively observe, adjust between theory and reality and try to do it yourself. Participants involved were a number of pilgrims and administrators consisting of 12 people consisting of 6 women and 6 men. Age of participants between 41-60 years, after being given lectures and demonstrations the level of knowledge of participants $100 \%$ in either category. These results are obtained through
\end{abstract}


evaluation of tests conducted after a series of training activities. Community service activities are effective in increasing the knowledge and skills of participants as posbindu cadres, namely by understanding knowledge related to general illness, preparation as a prospective pilgrimage and basic inspection actions in posbindu activities.

Keywords: Posbindu, Hajj and Umrah, Guidance

\section{PENDAHULUAN}

Kelompok bimbingan ibadah haji merupakan salah satu organisasi dakwah yang bertugas untuk membantu proses pelayanan ibadah haji di Indonesia. Kelompok bimbingan ibadah haji merupakan lembaga atau yayasan sosial islam dan pemerintah bergerak di bidang bimbingan manasik haji terhadap calon jemaah haji baik selama dalam pembekalan di tanah air maupun pada saat pelaksanaan ibadah di Arab Saudi. Kelompok bimbingan ibadah haji sebagai lembaga sosial keagamaan (non pemerintah) telah memiliki legalitas pembimbing melalui undangundang (Aziz, 2007).

Dalam pelaksanaanya, jemaah haji sudah mendapatkan pelayanan pemeriksaan kesehatan khusus sesuai dengan ketetapan pemerintah. Pelaksanaan pemeriksaan kesehatan jemaah haji merupakan bagian pelayanan rutin dan agar tidak dikonsentrasikan. Konsentrasi pelaksanaan pemeriksaan, baik waktu dan tempat dapat mengakibatkan penurunan mutu dan gangguan bagi pelayanan lain. Pemeriksaan kesehatan jemaah haji diselenggarakan secara kontinum dan komprehensif melalui dua tahapan (Kemenkes RI, 2010).

Pemeriksaan Kesehatan Tahap Pertama merupakan pemeriksaan kesehatan bagi seluruh jemaah haji di Puskesmas untuk mendapatkan data kesehatan bagi upaya-upaya perawatan dan pemeliharaan, serta pembinaan dan perlindungan. Pelaksanaannya dilakukan oleh Tim Pemeriksa Kesehatan Haji Puskesmas (Kemenkes RI, 2010).

Pemeriksaan Kesehatan Tahap Kedua merupakan pemeriksaan yang dilakukan untuk memperoleh data status kesehatan terkini bagi pemantauan dan evaluasi upaya perawatan, pemeliharaan, pembinaan dan perlindungan, serta rekomendasi penetapan status kelaikan pemberangkatan haji. Namun, pemeriksaan tersebut dilakukan sesuai dengan jadwal yang ditentukan (Kemenkes RI, 2010). Pada kenyataannya beberapa jemaah mengalami keluhan masalah kesehatan justru tidak pada saat jadwal pelaksanaan pemeriksaan kesehatan.

Pendirian Pos Pembinaan Terpadu (Posbindu) merupakan salah satu solusi untuk mengatasi masalah tersebut diatas, selain pemeriksaan dapat dilaksanakan 
berkala selama pelaksanaan bimbingan ibadah haji, jemaah juga dapat mengontrol kesehatannya. Posbindu merupakan salah satu Upaya Kesehatan Masyarakat (UKM) yang berorientasi kepada upaya promotif dan preventif dalam pengendalian Penyakit Tidak Menular (PTM) dengan melibatkan masyarakat, mulai dari perencanaan, pelaksanaan dan pemantauan serta penilaian. Masyarakat dilibatkan sebagai agen perubah sekaligus sumber daya yang menggerakkan Posbindu sebagai Upaya Kesehatan Berbasis Masyarakat (UKBM), yang diselenggarakan sesuai dengan kemampuan dan kebutuhan masyarakat (Kemenkes RI, 2019)

Kelompok Bimbingan Ibadah Haji An-Nur merupakan salah satu Kelompok Bimbingan Ibadah Haji dan Umroh di Kota Malang. Jumlah jemaah Haji di tahun 2020 sebanyak 80 jemaah. Usia jemaah didominasi usia 41-60 tahun sebanyak 62\%. Status pendidikan jemaah didominasi dengan pendidikan Sarjana (DIII, D4, S1 dan S2) sebanyak 47\%. Pekerjaan jemaah didominasi PNS sebanyak $25 \%$ dan wiraswasta sebanyak 22\%. Sebanyak 73\% jemaah pernah menderita sakit selama 3 bulan terakhir Sebanyak 22\% jemaah menderita sakit Hipertensi, 14\% Kolesterol, 14\% Diabetes, 14\% Asam lambung, 8\% Asam urat dan $12 \%$ penyakit lainnya. Selain itu, sebanyak $65 \%$ jemaah termasuk dalam status gizi obesitas.

\section{METODE}

Pelatihan masyarakat dikemas dalam bentuk pelatihan kader posbindu dengan materi pemeriksaan dasar meliputi pengukuran tekanan darah, berat dan tinggi badan, pengukuruan gula darah, asam urat, dan kolesterol serta penyuluhan kesehatan terkait penyakit yang umum terjadi dan persiapan calon jemaah. Sasaran kegiatan ini adalah anggota jama'ah dan pengurus sejumlah 12 orang. Kader ini dipilih karena diharapkan dia bisa berperan dalam pemantauan kesehatan dan menyalurkan pengetahuannya kepada para jemaah yang lain. kelak.

Metode pelaksanaan dalam kegiatan pengabdian masyarakat ini adalah dengan memberikan informasi dan ketrampilan melalui metode ceramah dan demonstrasi kepada kader terpilih. Metode demonstrasi yaitu metode yang menggunakan peragaan untuk memperjelas atau pengertian atau untuk memperlihatkan bagaimana melakukan sesuatu kepada peserta lain. Demonstrasi merupakan metode pembelajaran yang efektif, karena peserta didik dapat mengetahui secara langsung penerapan materi tersebut dalam kehidupan sehari-hari (Huda, 2013). Metode ini memiliki beberapa keunggulan diantaranya, dapat membuat pengajaran menjadi lebih 
jelas dan konkret, sehingga menghindari verbalisme (pemahaman secara kata-kata atau kalimat), peserta lebih mudah memahami apa yang dipelajari, proses pengajaran lebih menarik, dan peserta dirangsang untuk aktif mengamati, menyesuaikan antara teori dengan kenyataan dan mencoba melalukannya sendiri (Daradjat, 2016). Evaluasi hasil pembelajaran dilakukan melalui tes yang dilaksanakan setelah kegiatan. Hasil pengukuran pengetahuan dikelompokkan menjadi 3 kategori yaitu: baik (76\%-100\%),

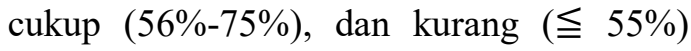
(Arikunto, 2013). Media yang digunakan dalam kegiatan ini berupa leaflet, power point presentasi, peralatan laboratorium berupa alat pelatihan tensimeter, stature meter, timbangan berat badan dan alat pengecekan gula darah, asam urat dan kolesterol.

\section{HASIL}

Kegiatan pengabdian kepada masyarakat ini dilaksanakan di gedung Kelompok Ibadah Haji dan Umroh An-Nur Kebonsari Kelurahan Kebonsari Kecamatan Sukun Wilayah Puskesmas Ciptomulyo. Peserta yang telibat merupakan beberapa jama'ah dan pengurus sejumlah 12 orang yang terdiri dari 6 perempuan dan 6 lakilaki. Usia peserta antara 41-60 tahun.

Tabel 1. Karakteristik peserta

\begin{tabular}{lccl}
\hline Karakteristik & $\mathrm{n}$ & $\mathrm{f}(\%)$ & Rerata \\
\hline Usia & & & 46,58 \\
Jenis kelamin & & & \\
Laki-laki & 6 & $50 \%$ & \\
Perempuan & 6 & $50 \%$ & \\
\hline
\end{tabular}

Hasil kegiatan pengabdian masyarakat menunjukkan setelah diberikan ceramah dan demonstrasi tingkat pengetahuan peserta $100 \%$ dalam kategori baik. Hasil ini didapatkan melalui evaluasi tes yang dilaksanakan setelah rangkaian kegiatan pelatihan.

\section{PEMBAHASAN}

Berdasarkan hasil yang didapatkan, kegiatan pengabdian masyarakat pendampingan kader posbindu ini efektif dilaksanakan. Hasil evaluasi pengetahuan setelah dilaksanakan kegiatan, 100\% pengetahuan peserta dalam kategori baik.

Pelatihan dan pendampingan kader posbindu dilaksanakan dengan metode ceramah dan demonstrasi. Pemilihan metode ini didasarkan pada karakteristik peserta dan keefektifitasannya. Metode ceramah merupakan metode tradisional dalam proses belajar mengajar. Meski metode ini lebih banyak menuntut keaktifan pengajar pada murid/pesertanya, tetapi metode ini tidak dapat ditinggalkan begitu saja dalam kegiatan pembelajaran, khususnya dalam pendidikan dan pengajaran tradisional (Satria dan 
Muhammad, 2018).

Menurut

Poerwadarminto

keterampilan adalah kecekatan, kecakapan atau kemampuan untuk melakukan sesuatu dengan baik dan cermat, dimana keterampilan seseorang dapat diasah dengan baik melalui pembelajaran dengan menggunakan metode demonstrasi. Demonstrasi adalah suatu cara penyajian pengertian atau ide yang dipersiapkan dengan teliti untuk memperlihatkan bagaimana cara menjalankan suatu tindakan, adegan atau memperlihatkan bagaimana menggunakan suatu prosedur (Nursalam, 2008 dalam Sundari, 2018). Selain itu tujuan metode demonstrasi adalah mendapatkan gambaran yang jelas tentang hal yang berhubungan dengan proses mengatur sesuatu, proses membuat sesuatu, proses bekerjanya sesuatu, proses mengunakannya, harapan yang membentuk sesuatu, membandingkan suatu cara lain dan untuk mengetahui serta melihat kebenaran sesuatu. Menurut kerucut Edgar dale, jika mendengar dan melihat demonstrasi, ia akan mengingat $50 \%$ dari apa yang didengar dan dilihat tersebut setelah dua minggu. Sedangkan bila partisipan mengucapkan sambil mengerjakan sendiri suatu materi pendidikan kesehatan, maka ia akan mengingat $90 \%$ dari materi tersebut. Dimana keterampilan motorik dan sikap partisipan diasah

(Nursalam, 2008 dalam Sundari, 2018).

Selain itu, Pemilihan metode pendidikan kesehatan harus mengingat besarnya kelompok sasaran, dimana responden hanya berjumlah 12 responden, waktu yang digunakan hanya satu kali, pertemuan dan tujuan yang ingin dicapai peningkatan pengetahuan peserta. Hal tersebut sesuai dengan penjelasan Nursalam (2008) dalam Sundari (2018), keefektifan suatu metode akan tergantung pada besarnya sasaran dan strategi pembelajaran.

\section{KESIMPULAN}

Kegiatan pengabdian kepada masyarakat "Pendampingan Kader Pos Pembinaan Terpadu (POSBINDU) Kelompok Bimbingan Ibadah Haji An-Nur Kebonsari Kelurahan Kebonsari - Kecamatan Sukun” telah berhasil meningkatkan pengetahuan dan kemampuan peserta sebagai kader posbindu. Hal ini dapat dilihat dari evaluasi yang dilakukan secara kualitatif dan kuantitaif yang menunjukkan peningkatan pengetahuan dan keterampilan peserta dalam melakukan pemeriksaan kesehatan dasar dalam pelaksanaan posbindu. Kegiatan pengabdian kepada masyarakat ini dapat dilakukan secara berkelanjutan dengan melibatkan lebih banyak pengurus kelompok untuk lebih menjamin keberlanjutan program selanjutnya. 


\section{DAFTAR PUSTAKA}

Arikunto, S. (2013). Prosedur Penelitian

Suatu Pendekatan Praktik. Jakarta: Rineka Cipta.

Aziz, Abdul dan Kustini (2007). Ibadah Haji dalam Sorotan Publik. Jakarta: Puslitbang Kehidupan Keagamaan.

Daradjat, Zakiyah (2016). Metodik Khusus Pengajaran Agama Islam.

Huda, Miftahul (2013). Model-Model Pengajaran dan Pembelajaran. Yogyakarta: Pustaka Belajar.

Kementerian Kesehatan RI. (2010).

Pedoman Pemeriksaan Kesehatan Jemaah Haji.

Kementerian Kesehatan RI. (2019),

Petunjuk Teknis Pos Pembinaan
Terpadu Posbindu bagi Kader. Jakarta :

Kementrian Kesehatan RI

Satria, A \& Muhammad, A (2018). Perbandingan Metode Pembelajaran Active Learning dengan Metode Pembelajaran Ceramah terhadap Motivasi Belajar Mahasiswa Keperawatan. Jurnal Ilmiah Kesehatan Pencerah, volume 7 no 2.

Sundari (2018). Keefektifan Pendidikan Kesehatan dengan Menggunakan Metode Demonstrasi terhadap Keterampilan dukun dalam Pijat Bayi di wilayah Kerja Puskesmas Babadan Kabupaten Ponorogo Tahun 2018. Global Health Science, volume 3 No. 4 